\title{
MULHERES, CASAMENTO E CARREIRA: UM OLHAR SOB A PERSPECTIVA SISTÊMICA FEMINISTA
}

WOMEN, MARRIAGE AND CAREER: A SYSTEMIC FEMINIST PERSPECTIVE

MARIANA GRASEL DE FIGUEIREDO

Universidade de Brasilia UnB, Brasilia, Brasil

\section{GLÁUCIA RIBEIRO} STARLING DINIZ

Instituto de Psicologia Universidade de Brasilia - UnB, Brasília, Brasil
Recebido em: 23/10/2017 Aprovado em: 18/01/2018
RESUMO: 0 artigo apresenta uma discussão teórica sobre a vivência de mulheres no casamento e na carreira a partir da perspectiva de gênero e sistêmica feminista. Apresentamos inicialmente uma discussão sobre o feminismo, 0 trabalho das mulheres e a possibilidade de investir na carreira profissional. Perpassamos aspectos históricos e conceituais que visam à contribuição para a compreensão da experiência das mulheres com a carreira na sociedade contemporânea. Articulamos, em seguida, questões de gênero com reflexões acerca das mulheres no casamento. Por fim, discorremos a respeito da terapia com base na perspectiva sistêmica feminista na interação casamento, carreira e gênero. A discussão ressalta 0 quanto a perspectiva sistêmica feminista é importante e útil para dar visibilidade às questões de gênero enfrentadas pelas mulheres no contexto do casamento e da carreira.

PALAVRAS-CHAVE: terapia sistêmica feminista; gênero; casamento; carreira.
ABSTRACT: This paper aims to present a discussion about the experience of women in marriage and in career by using a feminist systemic perspective combined with gender concepts. Initially we propose a discussion about feminism, women 's work and the possibility of having a professional career. We discuss historical and conceptual aspects in order to contribute to the understanding of women 's experience with combining a career and a marriage and family life in contemporary society. Then, it articulate the concepts of gender with the marriage of women. Finally, we describe the feminist systemic therapy in interaction and with a gender and a systemic feminist approach to marriage and family life. The discussion highlights how much the importance of adopting a systemic feminist perspective is important and useful to give light to gender issues dealt by women in their marriage and career.

KEYWORDS: systemic feminist therapy; gender; marriage; career.

\section{INTRODUÇÃO}

A questão da vivência das mulheres no casamento e na carreira é um fenômeno multideterminado que perpassa o social, o privado, a história e a cultura. Essa discussão torna-se relevante na medida em que nos ajuda a compreender aspectos importantes da vida das mulheres contemporâneas. As mulheres casadas que desenvolvem uma carreira podem enfrentar desafios significativos no que diz respeito à vivência e à conciliação dessas diferentes dimensões da vida. Pensar e problematizar criticamente a inserção de mulheres no mercado de trabalho é fundamental, principalmente, se levarmos em conta os estereótipos de gênero atribuídos a cada sexo presentes em nossa sociedade e as desigualdades deles decorrentes. O fato incontestável é que as mulheres são as principais vítimas dessas desigualdades, sobretudo no que diz respeito ao exercício profissional e salários (Yannoulas, 2013). 
Nossa compreensão conceitual sobre carreira segue a junção de definições clássicas encontradas nos estudos de Rhona Rapoport e Robert Rapoport (1976) e de Douglas Hall (2002). De acordo com os primeiros autores, carreira é entendida como uma sequência de trabalhos que exige um alto grau de compromisso e um caráter contínuo de desenvolvimento. Douglas Hall (2002) construiu seu conceito ao mesclar diferentes definições de carreira encontradas na literatura. Para o autor, seu significado refere-se à sequência individualmente percebida de atitudes e comportamentos associados com as experiências de trabalho e atividades durante a vida de uma pessoa. O conceito clássico da literatura nacional sobre carreira foi consolidado pelo pesquisador Joel Dutra na década de 1990. Ele define carreira como "as sequências de posições ocupadas e de trabalhos realizados durante a vida de uma pessoa" (Dutra, 1996, p. 17). O alto investimento de tempo e energia no desenvolvimento da carreira é um aspecto importante do mundo contemporâneo presente na vida tanto de homens quanto de mulheres.

A participação de mulheres no mercado de trabalho, desde os seus primórdios, foi marcada por controvérsias. Silvia Yannoulas e colaboradoras (2013) apontam que "a organização patriarcal da família e da esfera do trabalho" sempre privilegiou os homens, dando-lhes preferência e outorgando-lhes privilégios. A participação de mulheres no mundo do trabalho foi marcada por dissimetrias que sustentam a divisão sexual do trabalho. As autoras ressaltam que se por um lado ocorreu um fenômeno da feminização do trabalho, uma vez que mulheres começaram a ingressar em diversos campos profissionais, desenvolvendo carreiras em diversos contextos profissionais, de outro existe um número significativo de mulheres que permaneceu em campos de atividade tais como o setor da indústria têxtil, comércio (como empregadas), lavoura, serviços (empregadas domésticas), educação (professoras), formando um contingente de mão de obra que exerce suas profissões muitas vezes recebendo baixos salários e em condições de precarização.

Diante desse contexto cabe apontar a divisão do mundo em duas esferas - uma privada, destinada ao mundo feminino, e outra pública, destinada ao mundo masculino (Amâncio \& Oliveira, 2012; Scott, 1995; Yannoulas, 2013). Esse processo resultou em uma lógica dualista que produziu uma formação sexista tanto da vida privada quanto da vida pública, além de um processo de socialização diferenciado para os dois sexos. Silvia Yannoulas e colaboradoras (2013) ressaltam que esse processo de socialização contribuiu para exacerbar hierarquias e fomentar processos de dominação/subordinação. Decorre daí a importância de problematizar a dimensão de gênero, uma vez que as construções sociais acerca das atividades que cabem a um e outro sexo foram produzidas socialmente e demarcam lugares de experiência distintos para homens e mulheres, tanto da esfera pública quanto na vida privada, ou seja, no casamento, na família, no mundo do trabalho.

Este artigo, nesse sentido, tem por objetivo apresentar uma discussão teórica a respeito da vivência das mulheres no casamento e na carreira. Articulamos nessa reflexão conceitos das teorias de gênero e pressupostos da terapia sistêmica feminista. Buscamos, dessa forma, como pesquisadoras e terapeutas sistêmicas na área de casais e famílias, colaborar para uma reflexão crítica e uma prática clínica que torne 
visíveis aspectos da vida das mulheres profissionais casadas de nossa sociedade. Certos desafios pessoais das mulheres, bem como conflitos conjugais presenciados na clínica, por exemplo, podem ter relação com as desigualdades de gênero implícitas nos contextos do casamento, da família e do trabalho-carreira dos cônjuges.

\section{O PENSAMENTO SISTÊMICO E A TERAPIA FAMILIAR}

O surgimento da terapia familiar sistêmica foi influenciado pelo pensamento sistêmico (Vasconcellos, 2004). Essa forma de pensar propôs um novo paradigma em oposição ao pensamento positivista que dominava a ciência e estava vinculado a princípios de objetividade, neutralidade do/a cientista, simplificação e controle dos fenômenos - que eram percebidos dentro de uma estrutura de pensamento linear -, pautado por uma lógica de causa e efeito. Era dessa forma que as leis e regras que regem tanto o mundo privado quanto a vida social eram compreendidas e previstas. Tal modelo, entretanto, começou a mostrar-se insuficiente diante de um mundo que se tornava cada vez mais complexo.

A terapia familiar sistêmica compreende a família como um sistema de interação aberto, composto de subsistemas que se interligam e estabelecem padrões de interação que governam o funcionamento da família e influenciam o comportamento de seus membros (Carter \& McGoldrick, 2001; Minuchin, 2008; Nichols \& Schwartz, 2007). Nessa perspectiva, a família é considerada como um sistema, ou seja, ela está em interconexão com outros sistemas diferentes, tais como os sistemas sociais, políticos, econômicos, culturais. Sob influência do pensamento sistêmico, as conexões e relações ganham mais atenção do que as características individuais.

Esse entendimento perpassa a base de atuação das diferentes escolas de terapias sistêmicas familiares na medida em que tais escolas percebem os sistemas familiares como uma unidade em constante transformação e que mantém uma interdependência entre seus membros e com o meio. Os eventos ou partes não causam outros eventos, mas estão ligados de forma circular a muitos outros eventos e partes. Assim, os diferentes elementos que compõem um sistema influenciam e são influenciados uns pelos outros de forma contínua e recíproca.

Gênero, por sua vez, pode ser definido como o código de conduta que rege a organização social das relações entre homens e mulheres (Diniz \& Féres-Carneiro, 2012). Segundo Scott (1995), gênero fundamenta-se nas atribuições culturais feitas ao sexo masculino e feminino que estabelecem padrões e expectativas para mulheres e homens em cada cultura. É, conforme a autora, um elemento constitutivo de relações sociais baseadas em diferenças percebidas entre os sexos. O gênero é a principal forma de significar as relações de poder. As mudanças ocorridas nas relações sociais correspondem às transformações nessas representações de poder. A teoria de gênero aponta a importância do estabelecimento de condições igualitárias entre homens e mulheres nos diferentes contextos e destaca que ambos são sujeitos ativos na sociedade, independente dos estereótipos atribuídos aos sexos (Diniz, 2003; Diniz \& Féres-Carneiro, 2012; Macedo, 2009; Scott, 1995).

Nesse contexto e dentro do posicionamento novo paradigmático sistêmico surge o "The Women Project" liderado pelas pioneiras da Terapia Fa- 
miliar, Marianne Walters, Peggy Papp, Olga Silverstein e Betty Carter. O movimento tinha como objetivo introduzir reflexões de gênero nas práticas psicoterápicas sistêmicas com famílias e casais. Essas autoras argumentavam e defendiam que nenhuma intervenção está livre de valores associados ao sistema sexo/gênero (Diniz, 2003; Walters, 1994). O projeto alertava para a necessidade de os/as terapeutas sistêmicos/as estarem conscientes dos valores, crenças, preconceitos e julgamentos imbricados nas perguntas, na construção de hipóteses e nas intervenções feitas nas sessões com homens e mulheres atendidos/as. As discussões de gênero na terapia familiar, inspiradas pelos feminismos, deram origem ao que chamamos de terapia sistêmica feminista ou terapia feminista da família (Goodrich, Rampage, Ellman, \& Hasltea, 1990; Narvaz \& Koller, 2007; Penso \& Sant'Anna, 2015; Walters, 1994). A terapia sistêmica feminista incorpora, portanto, a crítica feminista às terapias familiares.

Nas últimas décadas, os papéis das mulheres no casamento e no trabalho sofreram profundas modificações (Diniz \& Feres-Carneiro, 2012; Jablonski, 2010; Rocha-Coutinho, 2007, 2012; Zordan, Falcke, \& Wagner, 2014). O casamento passou por diversas transformações. O fato é que, durante muito tempo, a vida conjugal e familiar era construída em torno de uma divisão clara de papéis pautada na diferença de poder entre os sexos. Os papéis de esposa, mãe e de responsável exclusiva pelos afazeres domésticos perderam a rigidez com que eram definidos na família tradicional e foram questionados. Embora na história as mulheres tenham sempre trabalhado, os movimentos sociais que surgiram nas últimas décadas do século XX ampliaram a possibilidade das mulheres adentra- rem o mundo do trabalho remunerado e, assim, dedicarem-se a uma carreira profissional.

A partir das considerações apresentadas, optamos por discutir neste artigo sobre a vivência das mulheres na interação com o casamento e a carreira através de uma perspectiva sistêmica feminista e de gênero. Dessa forma, pretendemos contribuir para a ampliação das reflexões sobre essa temática tão atual e presente nos meios sociais assim como em nossos consultórios psicológicos.

\section{TRABALHO DAS MULHERES, POSSIBILIDADES DE CARREIRAS E FEMINISMOS}

Michele Perrot (2012), em sua obra intitulada Minha história das mulheres, faz uma análise sobre o trabalho das mulheres ao longo da história. Perrot (2012) afirma que as mulheres sempre trabalharam. A maior parte delas, antes da segunda guerra mundial, eram camponesas ligadas ao trabalho rural. A vida das camponesas era regrada pela da família e pelo ritmo das produções dos campos.

As sociedades eram patriarcais e as hierarquias rígidas, o que refletia na divisão de funções, de tarefas e de espaços sociais. Ao homem cabia o trabalho da terra e das transações do mercado e à mulher cabia o cuidado com a casa, os filhos, a criação de animais, a horta. A mulher camponesa também era responsável por cuidar das vestimentas da família as quais, muitas vezes, ela mesma as tecia. Nesse contexto, além do trabalho rural, exerciam simultaneamente o trabalho doméstico.

A mulher camponesa dos séculos passados, segundo Perrot (2012), era uma mulher ocupada. Assim, pode- 
mos constatar o quanto, já nessa época, a mulher vivenciava a multiplicidade de funções na rotina diária da vida familiar e doméstica. Os diversos trabalhos realizados, no entanto, não eram remunerados. Foi a partir do século XVII que, na Europa, e em seguida nas outras partes do mundo, elas começaram a fazer parte do circuito monetário, tendo em vista o crescimento do mercado têxtil e de luxo nas cidades. O dinheiro que ganhavam, entretanto, era entregue aos seus cônjuges.

Por volta do século XVIII, por influência da industrialização e do consequente êxodo rural, a situação das camponesas começou a mudar. A partir desse momento elas aprenderam a mexer na terra e a gerenciar negócios. As guerras também foram responsáveis por diminuir a presença de homens no campo e possibilitar às mulheres assumirem os trabalhos que antes eram exclusivos deles. Com a industrialização, as mulheres, ainda meninas, iam trabalhar nas fábricas, direcionadas pelos seus pais. As fábricas ficavam nas cidades e eram também internatos onde as meninas moravam. No final do mês, o que recebiam pelo pagamento de seu trabalho era enviado para os pais (Perrot, 2012). Nessa época, as mulheres possuíam pouca autonomia em relação às suas escolhas profissionais ou mesmo em relação ao uso do dinheiro.

O casamento, naquele contexto, ainda era o destino natural da grande maioria das mulheres. Não acontecia por amor, mas era arranjado de acordo com os interesses das famílias. Desde cedo as meninas eram educadas para exercer as atribuições de dona de casa, esposa e mãe. Foi somente quando a família começou a se tornar menos patriarcal, na segunda metade do século XX, que as mulheres se modernizaram e começaram a dirigir automóveis, ter acesso à administração do dinheiro e usar talões de cheque (Perrot, 2012). Elas passaram a buscar trabalhos em lugares que começavam a empregar mulheres, como, por exemplo, os correios.

O fato é que o trabalho doméstico na história ocupou lugar central na vida das mulheres. Perrot (2012) aborda três tipos de trabalho doméstico realizado pelas mulheres europeias entre os séculos XVIII e XIX: o trabalho da dona de casa dos meios operários, da dona de casa burguesa e das empregadas domésticas. As ocupações da primeira eram: o serviço de limpeza da casa, a lavagem da roupa, as compras, a preparação das refeições. Essas mulheres eram encarregadas de tornar o custo de vida mais barato. $\mathrm{O}$ trabalho das operárias foi influenciado pela industrialização. Segundo a autora, esse tipo de trabalho era, no entanto, pouco qualificado, monótono, desconfortável, sujeito a riscos de acidentes, com jornadas diárias em torno de quatorze horas, sem garantias e sem possibilidade de carreira.

O trabalho das mulheres, de acordo com essa breve análise histórica, ficou predominantemente circunscrito ao espaço privado, era exercido de forma não remunerada e não valorizada. As atividades domésticas eram atribuídas e vistas como atribuições da mulher, independentemente de ela possuir outras atividades dentro ou fora de casa. O estereótipo social da mulher foi apoiado em sua condição biológica e justificou seu confinamento ao espaço doméstico (Zanello, 2016). A sua capacidade reprodutiva levou a uma idealização e naturalização das responsabilidades femininas quanto ao cuidado da casa e da família. A capacidade de gerar não era tida como produtiva $\mathrm{e}$, nesse contexto, a mulher representava o sexo desqualificado para a vida pública. 
Após o século XIX, com a industrialização, a mulher iniciou uma jornada de novas significações e conquistas no mundo do trabalho. A segunda guerra mundial trouxe às mulheres maior oportunidade de atuar e reivindicar seus direitos. A partir da modernidade, a mulher adentrou principalmente o setor terciário de serviços e passou a ocupar cargos como o de vendedora, secretária, enfermeira e o de professora. Essas profissões foram, durante muito tempo, associadas principalmente às mulheres, uma vez que reforçavam a ideia da mulher como cuidadora. Cabe ressaltar que, apesar de todas as mudanças que ocorreram tanto na vida social quanto no mundo privado, atualmente, em todo o mundo, ainda cerca de $75 \%$ das mulheres que trabalham o fazem neste setor (Perrot, 2012).

A partir da industrialização e das mudanças trazidas pelas duas grandes guerras, as mulheres intensificaram as vivências profissionais, conquistaram maior espaço no mundo do trabalho e começaram, inclusive, a aparecer em cargos de chefia. Os estereótipos de gênero e suas atribuições foram mudando na medida em que processos macrossociais, econômicos e culturais também mudaram.

Pensar o trabalho das mulheres historicamente, desde as camponesas dos séculos passados, até as mulheres profissionais do mundo contemporâneo, contribui para o entendimento da carreira das mulheres de hoje. Compreender suas origens leva-nos a reforçar, inclusive, o mérito das conquistas daquelas que optaram, na sociedade atual, por se dedicar a uma carreira.

No Brasil, a participação da mulher no mercado de trabalho da forma como vemos hoje, remunerada e com possibilidade de dedicação a uma carreira, tornou-se mais efetiva a partir da década de 1970 (Fontenele-Mourão, 2006). O empobrecimento das camadas médias, aliado ao aumento das despesas com educação dos filhos, saúde e outras necessidades consideradas básicas, impulsionou, especialmente nos anos de 1980, as mulheres casadas a buscar um trabalho fora de casa (Rocha-Coutinho \& Losada, 2007).

No início da década de 1990, a mulher consolidou sua participação no mercado de trabalho e hoje a mão de obra feminina já é superior a dos homens (Bruschini \& Lombardi, 2001; Coelho, 2006; Fontenele-Mourão, 2006). Todo este movimento contribuiu significativamente para a redefinição das atribuições sociais de gênero da mulher na contemporaneidade.

Os movimentos feministas das décadas de 1960 e 1970 foram protagonistas no processo de reconhecimento da mulher e de legitimação do espaço público como um espaço também seu (Fontenele-Mourão, 2006; Vianna \& Diniz, 2014; Zanello, 2016). Esses movimentos contribuíram para a desconstrução da naturalização das diferenças entre os sexos e evidenciaram as múltiplas relações de poder que perpassam o ser homem e o ser mulher no mundo (Diniz \& Féres-Carneiro, 2012).

Foi também o feminismo, compreendido em três ondas, que problematizou o conceito de gênero. Inicialmente, em sua primeira onda, marcada pela luta pelo sufrágio universal, o feminismo problematizou e tratou da construção social do feminino e do masculino. Em seguida, na segunda onda, o conceito de "gênero" foi introduzido para complementar o de "sexo" e não para substituí-lo (Zanello, 2016). Nesse momento em que os movimentos feministas buscavam construir teorias que expressassem a opressão da 
mulher, dois pilares epistemológicos se fizeram importantes: "a diferença sexual como um 'fato' sendo o gênero a construção social a partir destas diferenças e a noção de identidade como algo substancial, marcado pela constância” (Zanello, 2016, p. 227).

A terceira onda do feminismo, que surge a partir dos anos 1980, criticou esses dois pilares. O foco agora era problematizar, dentro da categoria "gênero", a dimensão cultural dos corpos biológicos. $\mathrm{O}$ sexo passa a ser visto como uma construção de gênero (Vianna \& Diniz, 2014; Zanello, 2016). O antigo pilar da identidade de gênero é contestado e sua característica substancial é substituída pela noção do fluido.

O feminismo teve um papel fundamental na luta pela igualdade de gênero e influenciou a mudança da família hierárquica, fundamentada sob o poder patriarcal (Bruschini \& Lombardi, 2009). O enfraquecimento da hierarquia nas relações de gênero, no final do século XX, ocasionou o surgimento de interações homem-mulher mais horizontais (Diniz, 2009; Rocha-Coutinho, 2012). As mulheres foram se dedicando cada vez mais às carreiras profissionais, fato que exigia delas maior investimento de tempo e energia no âmbito do trabalho.

As desigualdades de gênero, entretanto, ainda estão presentes no mundo contemporâneo. As realidades profissional e doméstica-familiar demandam exigências pautadas no sistema sexo-gênero. $O$ mundo do trabalho continua sendo definido por padrões masculinos. O preconceito e a discriminação decorrentes dessa construção histórica e social dificultam a ascensão das mulheres na carreira. Seus salários são inferiores aos dos homens e, ainda que ocupem a mesma função, elas são, de modo geral, excluídas das decisões organizacionais (Rocha-Coutinho, 2012; Tanure, Carvalho-Neto, \& Andrade, 2010).

Mulheres ganhando menos do que homens é uma realidade recorrente não apenas no Brasil, mas em todo mundo (Bruschini \& Lombardi, 2001). Ainda que ao longo dos anos seja percebida uma diminuição na diferença salarial entre os sexos, as mulheres continuam com rendimentos que correspondem a uma média de $68 \%$ do que o recebido pelos homens e, em cargos de chefia, elas recebem 77\% do salário dos homens (IPEA, 2016); independente do setor de atividade econômica em que trabalham, do tamanho da sua jornada de trabalho, do número de anos de estudo ou da sua posição na carreira.

Esse cenário mostra-se desafiador para as mulheres. Pesquisas sobre mulheres profissionais, executivas, no exercício de carreira no Brasil (Fontenele-Mourão, 2006; Lima, 2009; Rocha-Coutinho, 2007, 2012; Tanure, Carvalho-Neto, \& Andrade, 2010), identificam a presença de desafios como: preconceitos e discriminações; dificuldades de serem indicadas e de assumirem cargo de liderança; vivência de conflitos e de dificuldades de conciliação entre as demandas do trabalho e da família, como os cuidados com a casa e a questão da maternidade. Estes desafios constituem-se numa questão de gênero e seus enfrentamentos podem trazer um estado de sobrecarga para as mulheres.

Ingressar em uma carreira engloba a motivação pelo crescimento, pelo desenvolvimento profissional e por salários/rendimentos cada vez melhores. Para aqueles que a trilham, a carreira possui uma importância vital e pode ser uma das principais fontes de realização pessoal, status e reconhecimento social. As demandas da carreira 
muitas vezes envolvem viagens, horas extras, trabalhos de final de semana, fatores que acabam aumentando a sobrecarga da mulher.

O fato é que, se levarmos em conta o ambiente das grandes empresas, de modo geral extremamente competitivo e mutante, exige-se dedicação cada vez maior à carreira e, se tivermos em vista as demais funções exercidas no âmbito privado, é a carreira da mulher e não a do homem a que sofre maior pressão (Tanure, Carvalho-Neto, \& Andrade, 2010). Segundo destaca Fontenele-Mourão (2006), as mulheres precisam trabalhar com muito mais afinco e apresentar resultados superiores aos de seus colegas homens para garantirem sua posição na organização. As desigualdades de gênero são, portanto, uma realidade presente no mundo profissional.

$\mathrm{Na}$ última década, a partir do ano 2000, algumas empresas demonstraram movimentos no sentido de facilitar o desenvolvimento da carreira da mulher. Jornadas de trabalho mais flexíveis, a possibilidade do exercício do trabalho via home office, a presença de creches no ambiente de trabalho, dentre outros fatores, contribuíram para facilitar e manter a presença de mulheres no mundo do trabalho. Esses movimentos são, entretanto, incipientes, principalmente diante de um mercado de trabalho que ainda mantém uma estrutura tradicional que exige atuação em tempo integral e dedicação total aos objetivos da empresa (Rocha-Coutinho, 2012), ou seja, é marcado por padrões androcêntricos de funcionamento.

As mulheres são também questionadas sobre a capacidade de liderança e estão debaixo de um teto de vidro que, muitas vezes, as impede de atingirem posições mais altas (Fontenele-Mourão, 2006). A forma de gestão delas é avaliada, principalmente, como sendo baseada em sentimentos. Essa atribuição é fruto de estereótipos que associam o sexo feminino às questões emocionais e o sexo masculino às racionais. Pesquisas com homens e mulheres em posição de liderança não confirmam, no entanto, essa visão, e demonstram que ambos os sexos se caracterizam pela predominância do atributo "pensamento" em relação ao "sentimento" (Lima, 2009; Tanure, Carvalho-Neto, \& Andrade, 2010).

O exercício da maternidade é outro grande desafio encontrado pelas mulheres que trabalham. São muitas as pesquisas que abordam o tema (Beltrame \& Donelli, 2012; D'Elia, 2009; Maluf \& Kahhale, 2010; Rocha-Coutinho \& Barbosa, 2007; Tanure, Carvalho-Neto, \& Andrade, 2010). A conciliação da maternidade com a realização profissional é pregada muitas vezes como um ideal do mundo contemporâneo. Diante desse contexto a mulher tende a se perceber precisando do papel de mãe para se sentir completa. Cabe ressaltar, porém, que é justamente essa sobreposição de demandas, tidas como de responsabilidade prioritária da mulher, somadas aos cuidados com a casa, que pode lhes trazer estresse e sobrecarga (Tanure, Carvalho-Neto, \& Andrade, 2010).

Algumas pesquisas (Beltrame \& Donelli, 2012; Borges, 2013; Maluf \& Kahhale, 2012; Rocha-Coutinho \& Barbosa, 2007) começam a identificar que a realização da mulher não passa obrigatoriamente pela função de mãe. Os estudos demonstram que, no mundo contemporâneo, as mulheres estão fazendo escolhas norteadas mais pela carreira do que necessariamente pela maternidade. Neste sentido, podemos pensar que um movimento, ainda que incipiente, começa a surgir na direção 
da desconstrução dos antigos discursos. Rocha-Coutinho e Losada (2007) entrevistaram mulheres empresárias na cidade do Rio de Janeiro e identificaram que o significado da atividade profissional está marcado por expectativas e desejos que vão além daqueles relacionados à ideia de constituir uma família. Além disso, "assumir uma profissão configura-se, para elas, não apenas como fonte de sustento, mas, principalmente, como fonte de satisfação, algo que deveria ser assumido não só pelo retorno material, mas principalmente pelo prazer que proporciona" (Rocha-Coutinho et al., 2007, p. 497).

Escolher desenvolver-se em uma carreira, seja ela qual for, torna-se uma realidade para as mulheres da sociedade atual e pode, ao mesmo tempo, ser fonte de estresse e de realização. As mulheres casadas somam aos desafios encontrados no mundo do trabalho os desafios do casamento, dentre os quais as questões de gênero estão diretamente relacionadas. A este respeito, levantamos a discussão que se segue.

\section{O CASAMENTO E AS MULHERES: QUESTÕES DE GÊNERO}

As relações conjugais passaram por transformações significativas nos últimos séculos. No início das civilizações humanas as pessoas viviam de acordo com uma rígida divisão sexual dos papéis. As atividades e funções dos indivíduos nos grupos eram determinadas pelas questões sexuais e biológicas. As mulheres cuidavam do ambiente "doméstico", dos filhos, da coleta de frutas, e os homens cuidavam da caça, da pesca e da conquista de novas terras. Esse fato não implicava uma divisão desigual de poder ou uma valorização diferente do trabalho de homens e de mulheres (Pinsky, 1988).
A partir das evoluções advindas dos avanços na produção agrícola e da noção emergente de propriedade privada, por volta do século XVI, as relações sociais se modificaram e um novo modelo passou a operar. A adoção de uma forma patriarcal de funcionar concedeu ao homem, na condição de pai, o lugar de poder sobre sua prole e na condição de marido autoridade sobre sua esposa, seus empregados, da mesma forma que possuía com suas propriedades territoriais. É nesse momento que a noção de monogamia ganha força na relação conjugal (Ariès, 1986; Pinsky, 1988; Rocha-Coutinho \& Losada, 2007). A monogamia era exigida principalmente por parte da mulher e tinha a função de preservar a herança particular da família.

A família e o casamento possuíam a função de dividir a sociedade, que era organizada pelo Estado, em classes. Nesse percurso, a importância atribuída ao casamento está relacionada com a procriação e a geração de descendentes, reforçada pela lógica religiosa. Na Idade Média, a noção de família e casamento ainda era desconhecida. Ela tem início no final do século XV, ganha destaque no século XVII e se consolida no século XVIII. Até esse momento da História, o matrimônio era motivado, principalmente, por interesses econômicos (Ariès, 1986; Giddens, 2000). A função afetiva da família somente começou a ser uma realidade no século XVIII. Nessa época, a família volta-se mais para si mesma e inicia um processo de investimento na intimidade das relações, que passam a ser movidas cada vez menos por conveniência e cada vez mais por amor.

O casamento, até o século XIX, era centrado no poder patriarcal. A divisão tradicional do trabalho doméstico era pautada no sexo biológico. Assim, os homens eram responsabilizados 
pela manutenção financeira da família e as mulheres pela manutenção da ordem familiar em termos de produção doméstica e cuidados com os outros membros da família - marido e filhos/ as. Esse determinismo baseado nos sexos criou estereótipos para os dois. Nesse contexto, a mulher bem-sucedida era a que fosse escolhida por um homem. A mulher ficou restrita ao espaço do privado, do "sem valor" e o homem ao público, espaço valorizado pelo investimento em sua capacidade produtiva. No que tange ao mundo do trabalho, a mulher apoiava o desenvolvimento da carreira do marido e, mesmo quando saiu para trabalhar fora de casa, seu trabalho, durante muito tempo, foi visto como coadjuvante ao dele, como um complemento à renda da família (Rocha-Coutinho \& Losada, 2007).

A urbanização e a Revolução Industrial enfraqueceram a ordem patriarcal e as mulheres passaram a reivindicar um lugar de maior autonomia tanto na esfera familiar quanto pública. O conceito hegemônico de família, do pai provedor e da mãe restrita ao doméstico ampliou-se para acolher novas configurações como, por exemplo, famílias em que ambos os cônjuges trabalham fora em tempo integral.

Nesse momento da História, outra mudança significativa ocorrida no casamento entra em cena. Ela diz respeito à escolha do cônjuge. Nas diversas civilizações do passado, o casamento não era uma escolha a ser feita pelos cônjuges, uma vez que ela já estava determinada desde o dia do seu nascimento. A escolha era feita pela família, de acordo com os interesses de alianças, e tinha como base as relações de parentesco (MacFarlane, 1990). A reivindicação por um casamento pautado exclusivamente pela liberdade da escolha amorosa e não mais arranjado pelos interesses familiares ganhou força na década de 1860 .

O casamento no século XX é influenciado pelos valores emergentes. $\mathrm{O}$ surgimento e a consequente valorização das ideologias individualistas em detrimento das ideologias do patriarcado representam uma mudança bastante significativa nesse novo contexto. Gomes (1998) destaca, como marcadores da época, os movimentos sociais ocorridos da liberação sexual, dos feminismos, da entrada maciça das mulheres no mercado de trabalho.

Esse movimento de modernização dos valores e de maior abertura para se pensar a relação conjugal convivia, entretanto, com fortes resquícios do passado. A mulher, por exemplo, continuou submetida juridicamente ao marido até a década de 1970 . A partir de então foi permitida maior liberdade para elas adentrarem os espaços públicos. Além disso, as mulheres continuaram - durante muito tempo - confinadas ao espaço doméstico e à sua atribuição de cuidadora do lar, do marido e dos filhos. Todas essas funções ganhavam primazia sob sua possibilidade de inserção no mercado de trabalho e seu valor era superestimado em relação a qualquer outra possibilidade que ela quisesse trilhar.

No século XX, no final da década de 50, o surgimento da pílula anticoncepcional foi o grande acontecimento que marcou as relações entre homens e mulheres. No Brasil, ela chegou sob grande repressão da Igreja Católica. A possibilidade de separação entre reprodução e sexualidade permitiu uma revolução sexual na qual as mulheres começaram a se tornar protagonistas e donas do próprio corpo. Para a mulher dos séculos anteriores, o casamento significava a única forma de ter relação sexual. O controle da gravidez e o consequente adiamento da materni- 
dade abriram espaço para as mulheres adentrarem o universo dos estudos, do trabalho e, enfim, escolher por investir em uma carreira.

$\mathrm{O}$ sistema sexo-gênero estabelece padrões de expectativas tanto para os homens quanto para as mulheres e ordena os processos sociais cotidianos. No casamento, o gênero é o princípio organizador mais importante (Diniz, 2003). O ‘ser esposa e ser esposo' exige de homens e mulheres o cumprimento de atribuições de gênero definidas previamente pela sociedade e gera expectativas que recaem sob a forma como os cônjuges estabelecem sua dinâmica relacional. $\mathrm{O}$ fato de as mulheres dedicarem-se cada vez mais ao desenvolvimento de suas carreiras profissionais exige delas maior investimento de tempo no âmbito do trabalho. Surge assim na sociedade contemporânea o casamento de dupla-carreira, ou seja, aquele em que ambos os cônjuges encontram-se dedicados ao desenvolvimento e crescimento da carreira.

O modelo conjugal de dupla-carreira exige dos cônjuges uma dedicação intensa à carreira e, ao mesmo tempo, mantém o desejo de investir na vida a dois. Uma vez que ambos estão envolvidos com o desenvolvimento de suas carreiras, as atribuições sociais tradicionais de gênero necessitam de revisão e reorganização de modo a permitir o funcionamento da vida conjugal e doméstica. Os homens precisam assumir maior espaço no cuidado com a casa e os filhos e responsabilizarem-se por esse lugar. Da mesma forma, no cenário da dupla-carreira, outros cuidadores, como, por exemplo, os avós, possuem grande importância.

A forma de gestão das tarefas domésticas no casamento em que ambos os cônjuges trabalham fora também torna-se uma questão central na pauta do casal. Aos poucos, os homens começaram a ajudar suas esposas nos afazeres domésticos. Quando consideramos a relação entre gênero e divisão de atividades domésticas no casamento, entretanto, foram poucos os avanços. Ainda que possuam um trabalho fora de casa, o espaço privado da família e da casa continua sendo responsabilidade das mulheres. Wagner (2005) coloca, a este respeito, que pesquisadores do Brasil e dos Estados Unidos têm constatado que a divisão das tarefas domésticas ainda tende a seguir padrões relativamente tradicionais. Segundo a autora, mesmo nas casas onde as mulheres possuem um ganho financeiro maior do que os maridos, ou naquelas em que os maridos estão desempregados, elas realizam uma quantidade muito maior de atividades do trabalho doméstico do que eles.

Estudos realizados por Jablonski (2010) e Madalozzo, Martins, e Shiratori (2010) com o objetivo de analisar as diferentes participações dos sexos no trabalho doméstico identificaram que a presença de esposo, para as mulheres, aumenta o número de horas trabalhadas em casa. Já para os homens, a presença de esposa diminui essa participação. Outras pesquisas corroboram esses dados e apontam que a responsabilidade pelo espaço doméstico ainda segue a divisão tradicional de gênero (Bruschini, 2007; Rocha-Coutinho, 2007, 2012; Santos, 2014). Esse resultado é a tradução da divisão sexual do trabalho e dos estereótipos de gênero que se perpetuam até os dias de hoje.

O trabalho doméstico, quando exercido pelo homem, é visto como uma "ajuda" à mulher e não como responsabilidade compartilhada no cuidado com a casa. Jablonski (2010) entrevistou vinte membros de casais heterossexuais de classe média, com 
idades entre 30 e 45 anos (com pelo menos 5 anos de união), nos quais ambos trabalhavam fora de casa, e com a condição de terem ao menos um filho. $\mathrm{O}$ pesquisador identificou a falta de sintonia na percepção de homens e mulheres sobre a divisão de tarefas. As mulheres tenderam a percebê-la como mais assimétrica e os homens como mais equitativa. Esses dados revelam, mais uma vez, a operação dos modelos tradicionais de divisão do trabalho doméstico que acabam privilegiando os homens em detrimento das mulheres. Essa é uma questão de gênero que envolve a reorganização dos estereótipos sociais masculinos e femininos na família.

É fato que têm sido constatadas mudanças nesses estereótipos tradicionais, do homem voltado ao trabalho e sustento do lar e da mulher voltada às atividades domésticas, para uma divisão de tarefas mais igualitária entre homens e mulheres, principalmente com a entrada da mulher no mercado de trabalho. No entanto, o que se observa é que o casamento contemporâneo ainda se encontra sob forte influência de papéis sexuais socialmente predeterminados. O papel sexual, segundo Amâncio e Oliveira (2002), "constitui-se como uma norma que prescreve determinados comportamentos" (p. 46). Os papéis sexuais correspondem a um conjunto de comportamentos, expectativas e deveres aplicados à pertença de um indivíduo a um determinado grupo de sexo (Amâncio \& Oliveira, 2002). Assim, desde o início de sua vida, a mulher seria socializada para exercer uma atribuição social de gênero relacionada à família e o homem para uma função de provedor.

Interessante observar a presença de estudos que apontam que os maridos tendem a avaliar o casamento de forma mais positiva que as esposas (Falcke, Mosmann, \& Wagner, 2005; Perlim, 2006). Esses estudos concluem que parte dessa satisfação é devida ao fato de conseguirem conciliar sua expectativa pessoal e de carreira com as expectativas dentro do casamento. As mulheres, por sua vez, vivenciam a conjugalidade de forma mais tensa (Diniz, 1999; Diniz \& Perlin, 2005), uma vez que encontram mais dificuldade de conciliar as expectativas pessoais e profissionais com o exercício de funções tradicionais. Essa desigualdade de gênero no meio familiar e conjugal é tida como fator de estresse para mulheres (Carter \& McGoldrick, 2001; Papp, 2002).

As demandas decorrentes da vida doméstica e profissional limitam o tempo do casal em investir na própria conjugalidade e tornam-se outro desafio para os casais que trabalham, sobremaneira para os de dupla-carreira. A escassez de tempo é uma questão significativa nos dias de hoje (Heckler \& Mosmann, 2016). No contexto da vida do casal, a falta de rotinas que permitam que eles se encontrem pode ser geradora de conflitos na relação e afetar a qualidade da mesma (Fraenkel $\&$ Wilson, 2002). Além disso, o cansaço decorrente das vivências de múltiplas demandas do mundo do trabalho, da conjugalidade e da família interfere na disponibilidade dos cônjuges para a relação. Assim, a quantidade de tempo que o casal disponibiliza para si transforma-se em um outro desafio dos casamentos contemporâneos.

As pesquisadoras americanas Sarah Flood e Katie Genadek (2016) indicam o quanto o tempo despendido com o cônjuge é escasso nos casais em que ambos trabalham fora em tempo integral. As autoras ressaltam ainda o fato de que os maridos gostariam de possuir mais tempo com as esposas, mas 
que as esposas, por sua vez, gostariam de um maior tempo "de qualidade" com seus maridos, ao invés de somente terem mais tempo.

Esse ponto levanta outra interessante questão de gênero também observada por nós no trabalho na clínica psicológica. Os homens, muitas vezes, sentem-se satisfeitos em ter a esposa por perto, mas, para as mulheres, "estar perto" não é suficiente. As queixas delas, de modo generalizado, dizem respeito à falta de interação do marido em um nível mais íntimo ou à falta de iniciativa em convidá-las para programas que denotem o investimento na relação conjugal. A falta de tempo é, na grande maioria das vezes, utilizada como justificativa para esse impedimento (Flood \& Genadek, 2016).

Para que o casamento seja vivenciado pelas mulheres de forma mais igualitária, é essencial que os casais revejam os estereótipos de gênero aos quais estão submetidos e as posições de poder que ocupam na relação. Os casais precisam, além disso, fazer uso da flexibilidade e da negociação. No contexto em que ambos os cônjuges estão inseridos no mundo profissional, essas competências se tornam ainda mais necessárias.

Caso o investimento na vida profissional transcenda o trabalho em si e ganhe proporções nas quais a esposa ou ambos os cônjuges almejem desenvolver-se e crescer na carreira, o desafio torna-se ainda mais expressivo. Tal investimento demanda tempo e energia despendidos tanto em relação ao aprimoramento e crescimento da carreira quanto ao investimento no casamento. Cabe apontar também os desafios de gênero enfrentados pelas mulheres nesses contextos, fator que pode gerar estresse e comprometer tanto o ambiente de trabalho quanto a relação.

\section{A TERAPIA SISTÊMICA FEMINISTA NA INTERAÇÃO CASAMENTO-CARREIRA E GÊNERO}

A terapia familiar sistêmica percebe o grupo familiar como funcionando baseado na complementaridade dos papéis e na circularidade. Ao incorporar reflexões das teorias feministas, a perspectiva sistêmica amplia sua forma de ver e atuar, pois passa a considerar as influências de gênero e as diferenças de poder presentes tanto no casamento e na família quanto no mundo do trabalho (Diniz, 2003; Walters, 1994).

A perspectiva familiar sistêmica, de modo geral, introduz a percepção do casal, que é composta de três partes: dois indivíduos e uma relação: eu, você, nós. Dito de outra forma, assume-se que o vínculo conjugal é constituído por duas individualidades e uma conjugalidade. Nessa ótica, a dinâmica relacional do casal passa a ter mais destaque do que a individual. As questões de gênero, por sua vez, são essenciais no entendimento dessa dinâmica.

Virginia Satir (1995) destaca que o pensamento sistêmico aplicado ao casal entende que qualquer coisa que um integrante faz requer que o outro responda. Paralelamente, a resposta do outro molda seu próprio eu e impacta a dinâmica relacional. Essa sequência repetida dá origem a um modelo de funcionar que se traduz em normas para a relação.

A terapia sistêmica feminista busca uma compreensão das relações conjugais e familiares de forma mais igualitária e justa que permita olhar para as diferenças de percepções e vivências entre os cônjuges. Assim, busca perceber as especificidades de cada homem e de cada mulher no que diz respeito, por exemplo, à experiência no casamento e na carreira. As críti- 
cas feministas às terapias familiares tradicionais são anteriores aos movimentos sistêmicos pós-modernos do construtivismo e construcionismo social e questionam as desigualdades de gênero até então não consideradas nas práticas sistêmicas (Penso \& Sant'Anna, 2015; Walters, 1994).

Foi no final da década de 1970 , sob influência do movimento feminista, que esse enfoque surge dentro das terapias familiares (Goodrich et al., 1990; Nichols \& Schwartz, 2007). Apesar de passar a ser reconhecida como Terapia Sistêmica Feminista ou Terapia Feminista da Família, ela não se propôs a criar um novo modelo de terapia familiar, mas sim a incluir as questões de gênero e das diferenças de poder nas teorias e práticas sistêmicas (Diniz, 2003). O seu surgimento está relacionado com os questionamentos das terapeutas familiares pioneiras sobre a negligência em relação aos aspectos de gênero e também acerca do androcentrismo presente nos modelos e práticas da terapia familiar original.

Narvaz e Koller (2007) levantam as principais críticas feministas à terapia de família tradicional. Segundo as autoras, na medida em que as abordagens sistêmicas tradicionais concebem a família como um todo orgânico em busca de homeostase, não consideram as diferenças de poder dentro da família. Os pressupostos da circularidade e complementaridade a partir dos quais funciona a família desconsideram as diferenças de poder no sistema familiar em função das construções sociais em torno do sistema sexo-gênero que demarca posições e lugares de exercício de poder distintos para ambos os sexos.

A terapia sistêmica feminista entende que a opressão ocorre de forma linearmente causal e que não se pode atribuir igual responsabilidade a pes- soas que não têm o mesmo direito e acesso ao poder dentro de um sistema. O terceiro ponto da crítica feminista à terapia de família tradicional afirma que, ao negligenciar os aspectos de gênero presentes na dinâmica da vida conjugal e da família, as terapias sistêmicas não problematizam as atribuições sociais de gênero e funções familiares. Assim, foram mantidas as definições estáticas, binárias e rígidas sobre estes papéis, o que contribui para a manutenção da ordem patriarcal (Narvaz \& Koller, 2007). O quarto ponto relevante da crítica aponta que, ao valorizarem o poder, as hierarquias e a busca de autonomia dos indivíduos dentro da família, os modelos e estratégias iniciais das terapias sistêmicas pautaram-se em valores androcêntricos.

Nesse contexto, ficaram desvalorizadas outras formas de conexão relacional predominantemente desenvolvidas pelas mulheres, tais como a busca da intimidade e a valorização do cuidado para com a família. Além disso, foram idealizados valores tais como a autonomia e independência, em detrimento do pertencimento e da intimidade (Narvaz \& Koller, 2007). O quinto aspecto destaca que as terapias tradicionais idealizam a função paterna, colocam o homem como figura de poder e autoridade no sistema familiar e culpabilizam as mães, sem problematizar as posições de gênero tal qual são construídas na sociedade e na família. O penúltimo ponto da crítica feminista aponta que as terapias sistêmicas tradicionais não questionaram a instituição familiar tal como está construída em nossa sociedade e, assim, elas contribuíram para a manutenção das desigualdades de gênero e da opressão feminina. Por fim, ao desconsiderar as questões de gênero na formação e na supervisão, as terapias de família 
tradicionais deixam de considerar as especificidades vivenciadas pelos/as terapeutas, como se terapeutas também não tivessem uma inscrição $\mathrm{e}$ experiências tanto identitárias quanto relacionais em relação ao sistema sexo-gênero (Narvaz \& Koller, 2007).

As críticas feministas à terapia familiar buscaram contribuir para um novo posicionamento generificado dos/as terapeutas de casais e famílias. Ao mesmo tempo, buscaram dar visibilidade para as mulheres e homens que procuram atendimento. Nesse cenário torna-se fundamental a problematização dos estereótipos de gênero a que estão submetidas em seus próprios contextos relacionais e sociais. Desse modo, os/as terapeutas poderão também se empoderar e lutar por práticas mais igualitárias.

A interação trabalho/carreira com casamento/família é um desafio de gênero e diz respeito às múltiplas funções exercidas pelas mulheres nas relações conjugais, familiares, profissionais e sociais. Antes da entrada maciça de mulheres no mercado de trabalho, elas dedicavam-se aos cuidados da família e da casa para, depois, somar o papel profissional. A necessidade de conciliação carreira-casamento pode vir a ser um conflito enfrentado por elas e é comum os desafios desse processo serem levados como pedido de ajuda à clínica psicológica.

$\mathrm{O} / \mathrm{a}$ terapeuta familiar que se depara com esses tipos de demandas, quando informado/a por uma perspectiva sistêmica feminista, pode identificar as questões de gênero relacionadas que pesam sobre a cliente a fim de trabalhá-las de forma adequada. Isso porque esses conflitos podem prejudicar o desenvolvimento tanto da conjugalidade quanto da vida profissional e gerar um quadro de desequilíbrio capaz de trazer sofrimento e angústia para as mulheres. É comum, por exemplo, elas experimentarem o sentimento de culpa - ou por não conseguirem dedicar mais tempo à carreira ou à família (Lima, 2009; Rocha-Coutinho, 2012; Spindola \& Santos, 2004).

No que diz respeito à sobrecarga da mulher casada que opta por investir em sua carreira, Lima (2009) atesta, inclusive, que é frequente o levar tarefas do trabalho para casa. Esse fato impede as mulheres, muitas vezes, de se fazerem efetivamente presentes na vida familiar. Este quadro é ainda potencializado pelo uso das tecnologias (tais como celulares, tablets, computadores) fora do ambiente de trabalho. $\mathrm{Na}$ prática clínica ouvimos relatos de mulheres que se escondem no banheiro de casa para continuar uma tarefa não finalizada no ambiente de trabalho. Elas fazem isso para evitar um conflito com o esposo que cobra sua presença em casa e, ao mesmo tempo, suprir sua necessidade de dar conta de todo o trabalho, tendo em vista a cobrança profissional.

Nesse contexto, alguns autores, tais como Maria Lúcia Rocha-Coutinho (2007), falam da "dupla jornada da mulher", referindo-se ao trabalho e a casa. Peggy Papp (2002) propõe a ideia da tripla jornada da família, ao ressaltar as três esferas iguais de atividades: a jornada da mulher, a jornada do homem e a da vida familiar. Dessa forma, a autora pretende ir além da discussão sobre as negociações das tarefas domésticas entre o casal e busca estabelecer um diálogo no qual se confere igual importância ao trabalho e à família tanto na vida dos homens quanto das mulheres.

Peggy Papp (2002) identifica em sua prática clínica o quanto os casais continuam vivendo seus relacionamentos em termos da divisão tradicional de papéis. $O$ estereótipo de gênero 
se mistura ao estereótipo das tarefas, em que algumas são consideradas predominantemente femininas e outras masculinas. Neste sentido, a autora ainda coloca que os casais ficam presos a esta crença de que ele não tem capacidade emocional suficiente para se responsabilizar pelo relacionamento e pela vida familiar, enquanto ela não apenas tem a capacidade, mas também a responsabilidade de dar seguimento e administrar o relacionamento, além de encorajar o vínculo afetivo na família (Papp, 2002).

Conforme já apontamos, mesmo após as conquistas das mulheres no mundo profissional, elas continuam estando associadas ao lugar de cuidadora da família e de responsável pelo cuidado com a casa. A imagem da mulher na contemporaneidade, diferente da visão tradicional de esposa e mãe, integra a inserção no mercado de trabalho à sua função já existente de cuidadora. Ao adentrarem uma carreira, as mulheres podem impor para si, com base nos estereótipos invisíveis de gênero ainda presentes em nossa sociedade, a tarefa e/ou mesmo a obrigação de conciliar os papéis de administradora da vida familiar e da casa, passando a administrá-los em paralelo à carreira. $\mathrm{O}$ fato é que as mulheres, ao ocuparem esse lugar de responsáveis e cuidadoras, se sobrecarregam e esse processo pode gerar muito estresse e, consequentemente, comprometer sua saúde física e mental.

\section{CONSIDERAÇÕES FINAIS}

A discussão teórica presente neste artigo convida a refletir acerca do lugar das mulheres no contexto contemporâneo em função de seu envolvimento com a carreira e o casamento. Torna-se fundamental com- preendê-lo de forma mais ampla, sob a perspectiva sistêmica feminista e de gênero. Ao refletirmos sobre a experiência das mulheres no âmbito profissional e do casamento a partir de uma breve visão histórica até o período contemporâneo, percebemos as mudanças ocorridas nos estereótipos de gênero. Houve conquistas no mundo do trabalho que possibilitaram às mulheres experimentar o que antes era exclusivo ao mundo dos homens, por exemplo, a possibilidade de dedicar-se a uma carreira e à realização profissional.

O discurso social instaurado pelo patriarcado, entretanto, parece continuar sendo reproduzido no mundo contemporâneo, ainda que em menor velocidade e força do que no passado. Esse discurso torna invisível para as mulheres o lugar que ocupam e faz com que busquem estratégias para dar conta da multiplicidade de funções demandadas, como se o cuidado com a casa e os filhos fosse responsabilidade exclusiva ou prioritária delas. A vida profissional das mulheres que investem em uma carreira por si só já possui muitos desafios. A interação desta com as demais atribuições desempenhadas no âmbito privado intensifica suas experiências, podendo trazer prejuízos às mulheres.

É nosso entendimento que as influências do patriarcado e a divisão tradicional das atribuições de gênero pautadas no sexo biológico não fazem sentido na sociedade contemporânea. Tal fato fica evidente principalmente quando analisamos e colocamos em perspectiva a vivência de mulheres na interação carreira-casamento. Percebemos o quanto a perspectiva sistêmica feminista torna-se útil e extremamente relevante para dar visibilidade às questões de gênero presentes nessa interação, a fim de que homens e mu- 
lheres construam relações mais justas e igualitárias no âmbito do casamento e da carreira. Assim, poderão posicionar-se de modo mais consciente e protagonista. Da mesma forma, é necessário que as empresas e ambientes de trabalho revejam as condições impostas às mulheres e busquem formas alternativas de oferecer maior igualdade no meio profissional, bem como melhor qualidade de vida.

A reflexão promovida amplia a atuação da Psicologia Sistêmica ao integrar a perspectiva sistêmica feminista no contexto da carreira e do casamento. Nesse sentido, o pensar e o atuar da clínica sistêmica, ao considerar a crítica feminista, ajudam a promover uma vivência menos desigual entre homens e mulheres e, assim, são capazes de minimizar sofrimentos e estresses vivenciados por mulheres, casais e famílias na sociedade atual.

Essa reflexão também é relevante para o contexto social. Ao disseminar um conhecimento científico a respeito de mulheres na sua interação com a carreira e o casamento, oferece subsídios para que mulheres e homens ressignifiquem os antigos estereótipos de gênero. Ao trazer novos significados, pode contribuir para uma vivência mais leve dentro do casamento e da vida social como um todo. Ao mesmo tempo, colabora com a academia e para os achados científicos acerca da temática do gênero e da sua atuação dentro da família.

Acreditamos que o debate contido neste artigo pode abrir portas para novas formas de pensar aspectos importantes do mundo do trabalho e da experiência das famílias de hoje. $\mathrm{O}$ artigo não tem a intenção de esgotar o tema, pelo contrário, buscamos incentivar novas reflexões, questionamentos e pesquisas que articulem a perspectiva sistêmica feminista com questões relacionadas aos estereótipos sociais de gênero presentes na sociedade contemporânea.

\section{REFERÊNCIAS}

Amâncio, J. M. \& Oliveira, L. (2002). Liberdades condicionais: o conceito de papel sexual revisitado. Sociologia, Problemas e Práticas, 40, 45-61.

Ariès, $P_{n}$ (1986). História social da criança e da família (D. Flaksman, Trad., $2^{\text {a }}$ ed.). Rio de Janeiro: Guanabara.

Beltrame, G. R. \& Donelli, T. M. S. (2012). Maternidade e carreira: desafios frente à conciliação de papéis. Aletheia, 38/39, 206-217.

Borges, C. C. (2013). Mudanças nas trajetórias de vida e identidades de mulheres na contemporaneidade. Psicologia em Estudo, 18(1), 71-81.

Bruschini, C. (2007). Trabalho e gênero no Brasil nos últimos dez anos. Cadernos de Pesquisa. 37(132), 537-572.

Bruschini, C. \& Lombardi, M. R. (2001). Instruidas e trabalhadeiras: trabalho feminino no final do século $X X$. Cadernos Pagu, 17/18, 157-196.

Carter, B. \& McGoldrick, M. (2001). As mudanças no ciclo de vida familiar. Porto Alegre: Artes Médicas.

Coelho, S. V. (2006). Abordagens psicossociais da família. In J. G. Aun., M. J. Vasconcellos, \& S. V. Coelho (Orgs.), Atendimento sistêmico de famílias e redes sociais: fundamentos teóricos e epistemológicos (pp. 143233). Belo Horizonte: Ophicina de Arte e Prosa.

D'Elia, T. C. P. (2009). Mulher, maternidade e trabalho: dilemas contemporâneos. Dissertação de Mestrado, Programa de Pós-graduação em Psicologia Clínica, Pontifícia Universidade Católica do Rio de Janeiro. 
Diniz, G. R. S. (1996). Dilemas de trabalho, papel de gênero e matrimônio em casais que trabalham fora em tempo integral. In T. Féres-Carneiro (Org.), Relação amorosa, casamento, separação e terapia de casal (pp.101112). Rio de Janeiro: Coletâneas da ANPEP.

Diniz, G. R. S. (1999). Homens e Mulheres Frente à Interação Casamento-Trabalho: aspectos da realidade brasileira. In T. Féres-Carneiro (Org.), Casal e família: entre a tradição e a transformação (pp. 31-54). Rio de Janeiro: NAU.

Diniz, G. R. S. (2003). Gênero e Psicologia: questões teóricas e práticas. $R e$ vista Psicologia Brasil, 1(2), 16-21.

Diniz, G. R. S. (2009). O casamento contemporâneo em revista. In T. Feres-Carneiro (Org.), Casal e família: permanências e rupturas (pp. 135-156). São Paulo: Casa do Psicólogo.

Diniz, G. R. S. \& Féres-Carneiro, T. (2012). Casamento e família: uma reflexão sobre desafios da onjugalidade contemporânea In T. C. Viana, G. R. S. Diniz, L. F. Costa, \& V. Zanello (Orgs.), Psicologia Clínica e Cultura Contemporânea (pp. 430447). Brasília, DF: Liber Livros.

„Diniz, G. R. S. \& Perlin, G. (2005). Casais que trabalham e são felizes: mito ou realidade? Psicologia Clínica, 17(2), 15-29.

Dutra, J. S. (1996). Administração de carreiras: uma proposta para repensar a gestão de pessoas. Atlas: São Paulo.

Falcke, D., Mosmann, C., \& Wagner, A. (2005). Passando a história a limpo: o impacto das experiências da família de origem na conjugalidade. In A. Wagner (Ed.), Como se perpetua a família? A transmissão dos modelos familiares (pp. 6780). Porto Alegre: EDIPUCRS.
Flood, S. \& Genadek. K. (2016). Time for Each Other: Work and Family Constraints Among Couples. Journal of Marriage and Family, 78, 142-164.

Fontenele-Mourão, T. M. (2006). Mulheres no topo de carreira: flexibilidade e persistência. Brasília, DF: Secretaria Especial de Políticas para Mulheres. Fraenkel, P. \& Wilson, S. (2002). Relógio, calendários e casais: o tempo e o ritmo dos relacionamentos. In $\mathrm{P}$. Papp (Org.), Casais em perigo (pp. 77-117). Porto Alegre: Artmed.

Giddens, A. (2000). Mundo em descontrole: o que a globalização está fazendo de nós. Rio de Janeiro: Record.

Gomes, I. C. (1998). O sintoma da criança e a dinâmica do casal. São Paulo: Escuta.

Goodrich, T. J., Rampage, C., Ellman, B., \& Hasltead, K. (1990). Terapia feminista da familia. Porto Alegre: Artmed.

Hall, D. T. (2002). Careers in and out of Organizations. Londres: Sage.

Heckler, V. I. \& Mosmann, C. (2016). A qualidade conjugal nos anos iniciais do casamento em casais de dupla carreira. Psicologia Clínica, 28(1), 161-182.

Instituto de Pesquisa Econômica Aplicada - IPEA. (2016). O perfil da discriminação no mercado de trabalho. Brasília, DF: Autor.

Jablonski, B. (2010). A divisão de tarefas domésticas entre homens $\mathrm{e}$ mulheres no cotidiano do casamento. Psicologia: Ciência e Profissão, 30(2), 262-275.

Lima, G. S. (2009). Os desafios da carreira da mulher executiva no Brasil. Dissertação de Mestrado, Programa de Pós-graduação em Administração, Pontifícia Universidade Católica de Minas Gerais, Belo Horizonte. Madalozzo, R., Martins, S., \& Shiratori, L. (2010). Participação no mercado 
de trabalho e no trabalho doméstico: homens e mulheres têm condições iguais? Revista Estudos Feministas, 18(2), 547-566.

Maluf, V. M. \& Kahhale, E. M. S. P. (2010). Mulher, trabalho e maternidade: uma visão contemporânea. Revista Polêm!ca, 9(3), 143-160.

Macedo, R. M. S. (2009). Questões de gênero na terapia de familia e de casal. In L. C. Osório \&, M.E.P. Valle (Orgs.), Manual de terapia familiar (pp. 59-72). Porto Alegre: Artmed.

Minuchin, S. (2008). O encontro terapêutico. In S. L. W. Minuchin \& G. Simon (Orgs.), Dominando a terapia familiar (pp. 99-122). Porto Alegre: Artmed.

Narvaz, M. \& Koller, S. H. (2007). Feminismo e terapia: a terapia feminista da família - por uma psicologia comprometida. Revista Psicologia Clínica, 19(2), 117-131.

Nichols, M. P. \& Schwartz, R. C. (2007). Terapia familiar: conceitos e métodos. Porto Alegre: Artes Médicas.

Papp, P. (2002). Casais em perigo: novas diretrizes para terapeutas. Porto Alegre: Artmed.

Penso, M. A. \& Sant'Anna, T. C. (2015). A violência contra a mulher na perspectiva da terapia feminista da familia. Nova Perspectiva Sistêmica, 53, 95-110.

Perlin, G. D. B. (2006). Casamentos contemporâneos: um estudo sobre os impactos da interação família-trabalho na satisfação conjugal. Tese de Doutorado, Programa de Pós-graduação em Psicologia Clínica e Cultura, Universidade de Brasília (UnB), Brasília, DF.

Perrot, M. (2012). O trabalho das mulheres. In Minha história das mulheres (pp. 109-134). São Paulo: Contexto.

Pinsky, J. (1988). As primeiras civilizações (3a ed.) São Paulo: Atual.
Rapoport, R. \& Rapoport R. N. (1976). Dual-career families. First edition published by Harmonds worth. London: Penguin Books.

Rocha-Coutinho, M. L. (2003). Quando o executivo é uma "dama”: a mulher, a carreira e as relações familiares. In T. Féres-Carneiro (Org.), Família e casal: arranjos e demandas contemporâneas (pp. 57-77). Rio de Janeiro: PUC-Rio.

Rocha-Coutinho, M. L. \& Barbosa, Pr Z. (2007). Maternidade: novas possibilidades, antigas visões. Psicologia Clínica, 19(1), 163-185.

Rocha-Coutinho, M. L., \& Losada, B. (2007). Redefinindo o significado da atividade profissional para as mulheres: o caso das pequenas empresárias. Psicologia em Estudo, 12(3), 493-502.

Rocha-Coutinho, M. L. \& Coutinho, R. R. (2012). Mulheres brasileiras em posições de liderança: novas perspectivas para antigos desafios. Economia Global e Gestão, 16(1), 61-79.

Santos, L. (2014). Donas de casa, donas da própria vida? Problematizações acerca do trabalho (in)visivel e da saúde mental de mulheres (des)valorizadas. Tese de Doutorado, Programa de Pós-graduação em Psicologia Clínica e Cultura, Universidade de Brasília (UnB), Brasília, DF.

Satir, V. (1995). A mudança no casal. In M. Andolfi, C. Angelo, \& C. Saccu (Orgs.), O casal em crise (pp. 29-37). São Paulo: Summus.

Scott, J. W. (1995). Gênero: uma categoria útil de análise histórica. Educação \& Realidade, 20(2), 71-99.

Spindola, T. \& Santos, R. S. (2004). Trabalho versus vida em família. Conflito e culpa no cotidiano das trabalhadoras de enfermagem. Ciencia $y$ Enfermeria, 10(2), 43-52.

Tanure, B., Carvalho-Neto, A. M., \& Andrade, J. A. (2010). Executivas: 
carreira, maternidade, amores e preconceitos. RAE-eletrônica, 9(1), $1-23$.

Vianna, C. \& Diniz, G. (2014). Gênero, feminismos e saúde mental: implicações para a prática e a pesquisa em Psicologia Clínica. In V. Zanello \& A. P. Müller de Andrade (Orgs.), Sáude mental e gênero: diálogos, práticas e interdisciplinaridade (pp. 81-106). Curitiba: Editora Appris.

Wagner, A. (2005). Como se perpetua a família? A transmissão dos modelos familiares. Porto Alegre: EdiPUCRS.

Walters, M. (1994). Uma perspectiva feminista da terapia de familia. In R. Perelberg \& A. Miller (Orgs), Os sexos e o poder nas famílias (pp. 2746). Rio de Janeiro: Imago.

Yannoulas, S. C. (2013). Trabalhadoras: análise da feminização das profissões e ocupações. Brasília, DF: Abaré.

Zanello, V. (2016). Saúde mental, gênero e dispositivos. In M. Dimenstein, J. Leite, J. P. Macedo, \& C. Dantas (Orgs.), Condições de vida e saúde mental em contextos rurais (pp. 223246). São Paulo: Intermeios.

Zordan, E. P., Falcke, D., \& Wagner, A. (2014). Copiar ou (re)criar? Perspectivas histórico-contextuais do casamento. In A. Wagner (Org.), Como se perpetua a família? A transmissão dos modelos familiares. (pp. 47-65). Porto Alegre: EdiPUCRS.
MARIANA GRASEL DE FIGUEIREDO

Psicóloga, Terapeuta de Casais e Famílias, Doutoranda em Psicologia Clínica e Cultura pela Universidade de Brasília - UnB, Brasília, Brasil; Mestra em Psicologia Clínica pela Pontifícia Universidade Católica de São Paulo PUC-SP.

E-mail: marianafdelmonte@gmail.com

\section{GLÁUCIA RIBEIRO STARLING DINIZ}

Professora do Departamento de Psicologia Clínica, Instituto de Psicologia - Universidade de Brasília - UnB, Brasília, Brasil; Ph.D. pela United States International University, San Diego, CA, Estados Unidos.

E-mail: gdiniz@unb.br 